\title{
Escola unitária e princípio educativo em Gramsci: ensaios de compreensão à luz do caderno 12
}

\author{
Mestranda em Educação pela Universidade Estadual do Ceará \\ Betânia Moreira Moraes \\ Universidade Estadual do Ceará \\ Maria Susana Vasconcelos Jimenez \\ Professora da Universidade Estadual do Ceará
}

\section{Resumo}

O artigo explora as categorias Escola Unitária e Princípio Educativo, como base de compreensão da proposta educacional de Gramsci articulada à transição ao socialismo. Explicita que, no Caderno 12, o autor parte da constatação de que o sistema educacional italiano se encontra em crise, a qual se materializaria em uma cisão entre ensino técnico e ensino intelectual. O teórico revolucionário assinala que a referida crise do sistema escolar encontra uma solução na forma de uma escola única, que tem como base o princípio educativo. Gramsci pensa a Escola Unitária para o momento de transição do capitalismo ao socialismo, em que o proletariado tome o poder e instaure um novo sistema educacional. Palavras-chave: Escola Unitária; Princípio Educativo; Revolução Socialista.

\begin{abstract}
The article explores the categories of Unitary School and Educational Principle, as a basis for the understanding of Gramsci's educational proposal for the socialist transition. It notes that in his Number 12 Notebook, Gramsci attests that the crisis in the Italian educational system materializes itself in the partition between the technical and intellectual dimensions of schooling. According to the revolutionary author, that crisis would be solved by the establishment of an equal school, based upon an educational principle. Gramsci assumes the Unitary School for the transitional moment from capitalism to socialism, when the proletariat takes the power and creates a new educational system.
\end{abstract}

Keywords: Unitary School; Educational Principle; Socialist Revolution. 
$\mathrm{D}$ e início, é importante ressaltar que as considerações de Gramsci acerca da questão educacional não se restringem ao âmbito escolar. Observam-se, ainda, na obra do revolucionário sardo, distintas elaborações teóricas referentes à educação, que estão vinculadas aos diferentes momentos históricos que ele vivenciou.

Optamos por investigar o Caderno 12 do conjunto de 33 cadernos escritos no cárcere, por alguns motivos particulares, a saber: trata-se da principal obra em que o autor se refere mais diretamente sobre a educação, tanto em sentido geral como no aspecto específico da escola; constitui-se, de fato, a fonte bibliográfica gramsciana mais utilizada pelos estudiosos do campo da educação. Vale esclarecer a respeito dessa opção, que temos absoluta clareza de que tal leitura não seja suficiente para compreender o tratado de Gramsci sobre a educação. Passemos, então, ao nosso ensaio.

A origem do Fascismo coincidiu com uma grave crise social aberta na Itália, face sua participação na primeira grande guerra, e com a impossibilidade da revolução socialista se expandir a nível internacional. A ideologia ${ }^{1}$ dominante, nessa época, apregoava o patriotismo, o nacionalismo, uma espécie de ultra-valorização do Estado, portanto, os alunos aprendiam na escola a ter amor a sua pátria, amor esse que deveria se expressar no cumprimento das leis regidas pelo Estado.

Em meio a esse cenário histórico, o filósofo Giovanni Gentile ocupou o cargo de ministro da instrução pública no governo fascista e, em 1923, fez vigorar uma reforma no sistema educacional, denominada Reforma Gentille. Nesse momento, a escola foi utilizada como estratégia política, ou seja, como um dos instrumentos disseminadores do ideário presente no Fascismo, com a intenção de criar nos indivíduos uma nova maneira de compreender a realidade com o objetivo de manter a ordem vigente que se consolidava após a tomada do poder estatal pelo movimento fascista em 1922.

Naquele momento histórico, estavam ocorrendo uma série de

1 Há um estudo bastante interessante que apanha a ideologia no seu caráter ontológico, e mais, versa sobre a imbricação ontológica entre educação e ideologia. Cf. Costa (2007). 
transformações no complexo educacional em função do processo de crise do modo de vida que se instaurou na Itália. Nas palavras de Gramsci (2004, p. 32), com o advento da sociedade moderna, "as atividades práticas se tornaram tão complexas, e as ciências se mesclaram de tal modo à vida, que cada atividade prática tende a criar uma escola para os próprios dirigentes e especialistas". Nesse contexto, paralelamente ao tipo de escola tradicional, humanista, "destinado a desenvolver em cada indivíduo humano a cultura geral ainda indiferenciada, o poder fundamental de pensar e de saber orientar-se na vida" (GRAMSCI, 2004, p. 33), foi sendo criado todo um sistema de ensino com o objetivo de ensinar especificamente o conteúdo necessário ao desempenho de determinada atividade prática profissional. Nas suas palavras,

Na escola atual, em função da crise profunda da tradição cultural e da concepção da vida e do homem, verifica-se um processo de progressiva degenerescência: as escolas de tipo profissional, isto é, preocupadas em satisfazer interesses práticos imediatos, predominam sobre a escola formativa, imediatamente desinteressada. $\mathrm{O}$ aspecto paradoxal reside em que este novo tipo de escola aparece e é louvado como democrático, quando na realidade, não só é destinado a perpetuar as diferenças sociais, como ainda a cristalizá-las em formas chinesas (GRAMSCI, 2004, p. 49, grifo nosso).

Gramsci nos chama a atenção para o aparente caráter democrático dessa escola de tipo profissional, que por ser ampliada em quantidade, garantindo um maior acesso dos indivíduos à educação, é apresentada pelo Estado como uma escola democrática ${ }^{2}$, contudo, nesse momento, Gramsci já analisava que essa escola, ao contrário de democrática, visava, através da satisfação de "interesses práticos imediatos", a formar rapidamente um contingente de operários qualificados a operar nas fábricas - cabe sublinhar que o capitalismo se encontrava em ascensão, mediante o avanço do processo de industrialização; essa escola era destinada somente para os filhos dos trabalhadores, como veremos mais adiante.

$\mathrm{Na}$ velha escola, antes da reforma Gentile, o princípio educativo era

2 Sobre os limites da democracia e da cidadania, verificar Tonet (2005). 
o ideal humanista, ou seja, o que determinava a organização do programa e das disciplinas da escola eram aqueles conteúdos necessários à transmissão do legado histórico produzido pela humanidade, para que o indivíduo pudesse se conhecer, enquanto sujeito do gênero humano e se perceber consciente de sua vida e da humanidade a qual pertencia. Esse era um "elemento essencial da vida e da cultura nacionais", como podemos observar na citação que se segue:

$\mathrm{Na}$ velha escola, o estudo gramatical das línguas latina e grega, unido ao estudo das literaturas e histórias políticas respectivas, era um princípio educativo na medida em que o ideal humanista, que se personifica em Atenas $e$ Roma, era difundido em toda a sociedade, era um elemento essencial da vida e da cultura nacionais [...] As noções singulares não eram aprendidas com vistas a uma imediata finalidade prático-profissional: tratava-se de algo desinteressado, pois o que contava era $\mathrm{o}$ desenvolvimento interior da personalidade, a formação do caráter através da absorção e da assimilação de todo o passado cultural da civilização européia moderna. Não se aprendia o latim e o grego para se falá-los, para trabalhar como garçom, intérprete ou correspondente comercial. Aprendia-se para conhecer diretamente a civilização dos dois povos, pressuposto necessário da civilização moderna, isto é, para ser e conhecer conscientemente a si mesmo (GRAMSCI, 2004, p. 45-46, grifos nossos).

O marxista italiano, nesse momento, fala especificamente das consequiências da Reforma Gentile, na escola média, pois, antes da Reforma, o aluno acumulava uma série de conhecimentos, na perspectiva acima e abaixo transcritas, e, depois da Reforma, o aluno passou a chegar à escola média sem essa bagagem de conhecimentos e, quando se deparava com o ensino abstrato da filosofia, sem relação com a sua vida enquanto partícipe do gênero humano, ele acabava por decorar frases filosóficas que não cumpriam seu papel formativo. Nos termos do autor:

As línguas latina e grega eram aprendidas, mecanicamente, mas existem muita injustiça e impropriedade na acusação de mecanicidade e aridez. Lida-se com adolescentes, aos quais é preciso fazer com que adquiram certos hábitos de diligência, de exatidão, de compostura até mesmo física, de concentração psíquica em determinados assuntos, que só podem adquirir mediante uma repetição mecânica de atos disciplinados e 
metódicos. Um estudioso de quarenta anos seria capaz de passar dezesseis horas seguidas numa mesa de trabalho se, desde menino, não tivesse assimilado, por meio da coação mecânica, os hábitos psicofísicos apropriados? Se se quer selecionar grandes cientistas, ainda é preciso grandes cientistas, ainda é preciso partir deste ponto e deve-se pressionar toda a área escolar para conseguir fazer com que surjam os milhares ou centenas, ou mesmo apenas dezenas de estudiosos de grande valor, necessários a toda civilização (não obstante, podem-se obter grandes melhorias neste terreno com a ajuda dos subsídios científicos adequados, sem retornar aos métodos pedagógicos dos jesuítas (GRAMSCI, 2004, p. 46).

Gramsci está se referindo, então, à guinada que deu a escola com a Reforma, no seio da qual essas críticas tornam-se presentes. Tais críticas são, então, consideradas injustificadas para Gramsci, que entende que para desenvolver certos hábitos nos adolescentes, era necessário aplicar-se uma disciplina rigorosa. Podemos entender, ademais, que essas críticas não eram aleatórias, não temos conhecimento dos teóricos que realizavam a crítica ao ensino tradicional. Naquele momento, podemos entender que, como a ciência não é neutra, deveria tratar-se de intelectuais que optavam por contribuir para perdurar a ordem vigente ainda que consciente ou inconscientemente.

Será muito difícil encontrar uma matéria que substitua o latim e o grego, que provoque os resultados educacionais alcançados com o ensino dessas línguas. Em comum acordo com Manacorda (1990, p. 250), entendemos que a análise de Gramsci acerca do latim significa "uma serena avaliação histórica da função que teve o latim, mas que não tem mais e não mais poderá ter", ou seja, não se trata de retornar à escola tradicional, ao ensino do grego e do latim e sim encontrar um conteúdo que propicie o desenvolvimento intelectual desencadeado pelo ensino dessas línguas nas sociedades de Atenas e de Roma. O estudo, na sua maior parte, deve realizar-se de forma desinteressada, ou seja, não deve servir para uma atividade prática imediata, embora deva ser rico em noções concretas, para facilitar a aprendizagem do aluno. Nas palavras precisas de Gramsci (2004, p. 48-49): 
Será necessário substituir o latim e o grego como fulcro da escola formativa e esta substituição será feita; mas não será fácil dispor a nova matéria ou a nova série de matérias numa ordem didática que dê resultados equivalentes no que toca à educação e à formação geral da personalidade, partindo da criança até chegar aos umbrais da escolha profissional. De fato, nesse período, o estudo ou a maior parte dele deve ser (ou assim parecer aos discentes) desinteressado, ou seja, não deve ter finalidades práticas imediatas ou muito imediatas, deve ser formativo ainda que "instrutivo", isto é, rico de noções concretas.

$\mathrm{Na}$ passagem, que apresentamos a seguir, por sua vez, Gramsci (2004, p. 43) nos esclarece sobre o impacto que a Reforma Gentile causou no sistema escolar italiano, provocando uma cisão significativamente mais profunda do que a já existente entre os diversos níveis de ensino:

A fratura determinada pela reforma Gentile entre a escola primária e média, por um lado, e a escola superior por outro. Antes da reforma, uma fratura desse tipo existia, de modo marcado, somente entre a escola profissional, por um lado, e as escolas médias e superiores, por outro: a escola primária era colocada numa espécie de limbo, por algumas de suas características particulares.

Nesse sentido, Gramsci (2004, p. 39) chama a atenção para o fato de que a transformação necessária à escola, precisa romper com a fase romântica e adentrar na fase clássica, na qual os fins orientam os meios adequados de atingí-lo.

Ainda se está na fase romântica da escola ativa, na qual os elementos da luta contra a escola mecânica e jesuítica se dilataram morbidamente por razões de contraste e de polêmica: é necessário entrar na fase "clássica", racional, encontrando nos fins a atingir a fonte natural para elaborar os métodos e as formas.

No parágrafo seguinte, Gramsci (2004, p. 33, grifos nossos) nos disserta acerca do momento em que se discutia a reforma:

A divisão fundamental da escola em clássica e profissional era um esquema racional: a escola profissional destinava-se às classes instrumentais, enquanto a clássica destinava-se às dominantes e aos intelectuais. $\mathrm{O}$ desenvolvimento da base industrial, tanto na cidade como no campo, gerava a crescente do novo tipo de intelectual urbano: desenvolveu-se, ao lado da 
escola clássica, a escola técnica (profissional mas não manual), o que põe em discussão o próprio princípio da orientação concreta de cultura geral, da orientação humanista de cultura geral fundada na tradição grecoromana. Esta orientação, uma vez posta em discussão, foi afastada, pode-se dizer, já que sua capacidade formativa era em grande parte baseada no prestígio geral e tradicionalmente indiscutido de uma determinada forma de civilização.

Naquele momento, estava se rediscutindo o princípio que deveria reger a educação, em decorrência do "desenvolvimento da base industrial", ou seja, colocava-se em discussão o princípio humanista próprio das escolas tradicionais. Nesse cenário histórico, Gramsci admite que o desenvolvimento industrial requeria uma escola profissional, "mas não manual", ou seja, era necessário ao próprio desenvolvimento industrial da sociedade moderna que a escola formasse "um novo tipo de intelectual urbano", por conseguinte "a divisão fundamental da escola em clássica e profissional era racional".

Nessa análise do revolucionário italiano, entendemos que o mesmo admite a necessidade de se reformar o sistema educacional para formar os profissionais da indústria, pois Gramsci enxergava que o problema não estava na industrialização e sim na maneira adotada pelo governo para resolver essa problemática. Conforme advogava o autor,

A luta contra a velha escola era justa, mas a reforma não era uma coisa tão simples como parecia; não se tratava de esquemas programáticos, mas de homens, e não imediatamente de homens que são professores, mas de todo o complexo social do qual os homens são expressão [...] O fato de que um tal clima e um tal modo de vida tenham entrado em agonia e a escola se tenha separado da vida determinou a crise da escola. Criticar os programas e a organização da escola disciplinar da escola significa menos do que nada, se não se levam em conta estas condições (GRAMSCI, 2004, p. 44-45).

Por que a crítica à velha escola era justa, nos termos de Gramsci? Porque se tratava de um modelo de escola que refletia, sobretudo, o modelo de sociedade então existente e que entrava em agonia.

Aquele momento de grandes transformações no processo produtivo é 
colocado pelo autor dos Cadernos do Cárcere como algo necessário ao desenvolvimento da sociedade. Gramsci considera que toda tentativa de barrar ou negar o desenvolvimento advindo do processo de complexificação social, redundaria numa tentativa frustrada. Para o autor tal processo tinha por raiz o crescimento industrial, denominado por ele de "desenvolvimento orgânico necessário".

Portanto, surge a necessidade de modificar o processo de formação dessa cisão que ocorre entre essas duas categorias distintas, o qual consiste em formar o técnico político, superando a sua falta de entendimento das questões que regem a administração do processo produtivo e, por outro lado, formar funcionários especialistas que sejam capazes de deliberar, tomar decisões acerca de questões políticas. Pois, um dirigente político que só esteja preparado para versar de forma abstrata sobre questões jurídicas, ou seja, afastado dos problemas reais que sofre a população, se torna um perigo para a vida estatal, uma vez que ele não terá condições de criar ou, pelo menos, optar pela alternativa mais acertada acerca das soluções apontadas pelos especialistas técnicos.

Gramsci assinala que essa crise do sistema escolar encontra uma solução na forma de uma Escola Unitária. Em suas palavras:

A crise terá uma solução que, racionalmente, deveria seguir esta linha: escola única inicial de cultura geral, humanista, formativa, que equilibre de modo justo o desenvolvimento da capacidade de trabalhar manualmente (tecnicamente, industrialmente) e o desenvolvimento das capacidades de trabalho intelectual. Deste tipo de escola única, através de repetidas experiências de orientação profissional, passar-se-á a uma das escolas especializadas ou ao trabalho produtivo (GRAMSCI, 2004, p. 33-34).

Uma escola "única" comum a todos, ou seja, uma mesma escola para todos os indivíduos, contraposta a cisão entre o ensino técnico destinado às classes subalternas e o ensino humanista, intelectual destinado as classes dominantes; no intuito de promover um equilíbrio entre formar no aluno a capacidade de trabalhar manualmente, assim como desenvolver o exercício do trabalho intelectual. Contudo, somente depois de adquirir uma série de 
conhecimentos, nas palavras do revolucionário: "de uma consciência moral e social sólida e homogênea" (GRAMSCI, 2004, p. 39), passar-se-á a uma das escolas técnicas ou ao processo de trabalho. Gramsci defende o aprendizado autônomo e espontâneo do aluno somente numa fase em que este obteve uma "base já atingida de 'coletivização' do tipo social" (GRAMSCI, 2004, p. 39), ou seja, somente depois de o aluno ter se apropriado de todo um legado de conhecimento produzido pelo conjunto da humanidade.

Já aqui o teórico sardo nos traz considerações acerca de como deve se dar a organização da Escola Unitária e a quem compete garantir essa educação para toda a população - segundo propõe, ao Estado. Assim, declara:

Um ponto importante, no estudo da organização prática da escola unitária, é o que diz respeito ao currículo escolar em seus vários níveis, de acordo com a idade e com o desenvolvimento intelectual-moral dos alunos e com os fins que a própria escola pretende alcançar. A escola unitária ou de formação humanista (entendido este termo, "humanismo", em sentido amplo e não apenas em sentido tradicional) ou de cultura geral, deveria assumir a tarefa de inserir os jovens na atividade social, depois de tê-los levado a um certo grau de maturidade e capacidade para a criação intelectual e prática e a uma certa autonomia na orientação e iniciativa. A escola unitária requer que o Estado possa assumir as despesas que hoje estão a cargo da família no que toca à manutenção dos escolares, isto é, requer que seja completamente transformado o orçamento do ministério da educação nacional, ampliando-o enormemente e tornando-o mais complexo: a inteira função de educação e formação das novas gerações deixa de ser privada e torna-se pública, pois somente assim ela pode abarcar todas as gerações, sem divisões de grupos ou castas (GRAMSCI, 2004, p. 36 , grifos nossos).

Como vimos acima, Gramsci começa falando acerca do currículo, alertando que o currículo precisa estar vinculado à função da escola em desenvolver o ensinamento de uma moral aos alunos, entendendo moral como um conjunto de normas e valores que regem uma sociedade e que sem determinadas regras não há convivência possível entre os seres humanos. Coloca-nos, também, a necessidade da escola unitária assumir a função de 
ingressar os indivíduos no processo de trabalho, sem, contudo, poder restringir-se a uma educação que forme exclusivamente para o trabalho, uma vez que fica muito claro em suas palavras o apelo à "escola unitária ou de formação humanista”. Aponta, por fim, a necessidade do Estado assumir as despesas educacionais, desresponsabilizando a família dessa tarefa.

Nesse momento sócio-histórico, de Ditadura Revolucionária do Proletariado, se abriria a possibilidade de utilizar-se a educação como estratégia política do Estado operário, contribuindo para a superação da cisão entre trabalho manual e intelectual, pois, ao mesmo tempo em que seria organizado o processo produtivo, de acordo com o trabalho livre associado, a escola e as demais instituições estariam voltadas para formar novos indivíduos para viverem nessa nova forma de sociabilidade que começaria a ser implantada com a tomada do poder por parte dos comunistas. De acordo com Nosella (1992, p. 115),

Sem dúvida, existe uma relação vital entre Escola Unitária e Sociedade Unitária. Não uma relação mecânica de causa e efeito; é uma relação do tipo orgânico cujo princípio vital e central, porém, não parte da escola e sim do Estado que coordena a sociedade ou do Partido.

Essa observação formulada por Nosella (1992) converge com a posição do revolucionário sardo acerca da necessidade de superação da lógica do capital. Pois, para o secretário geral do partido Comunista italiano,

O advento da escola unitária significa o início de novas relações entre trabalho intelectual e trabalho industrial não apenas na escola, mas em toda a vida social. $O$ princípio unitário, por isso, irá se refletir em todos os organismos de cultura, transformando-os e emprestandolhes um novo conteúdo. [...] Num novo contexto de relações entre a vida e cultura, entre trabalho intelectual e trabalho industrial as academias deveriam se tornar a organização cultural (de sistematização, expansão e criação intelectual) daqueles elementos que, após a escola unitária, passarão para o trabalho profissional, bem como um terreno de encontro entre estes e os universitários (GRAMSCI, 2004, p. 40, grifo nosso).

Nessa passagem, fica evidente a perspectiva revolucionária assumida por Gramsci na elaboração da Escola Unitária, ao retratar como deveria se 
reorganizar o sistema educacional num momento em que começassem a se estabelecer novas relações entre trabalho manual e intelectual. Entendemos, em breves palavras, que este seria um momento em que os trabalhadores começariam a organizar livremente a produção dos meios de subsistência de acordo com as necessidades da população e não do mercado, assim como teriam voz ativa nas decisões acerca das soluções dos problemas sociais encaminhadas pelos dirigentes políticos de um novo Estado, o Estado operário.

Gramsci nos traz maiores detalhes metodológicos sobre como deveria organizar-se essa Escola Unitária na citação abaixo - é importante observar que o referido texto é bastante utilizado por diversos autores e muitas vezes descolada do contexto de sua obra, o que nos permite imaginar um Gramsci simplesmente teórico da educação. Senão vejamos:

A escola unitária deveria corresponder ao período representado hoje pelas escolas primárias e médias, reorganizadas não somente no que diz respeito ao método de ensino, mas também no que toca à disposição dos vários graus da carreira escolar. O nível inicial da escola elementar não deveria ultrapassar três-quatro anos e, ao lado do ensino das primeiras noções "instrumentais" da instrução (ler, escrever, fazer contas, geografia, história), deveria desenvolver sobretudo a parte relativa aos "direitos e deveres", atualmente negligenciada, isto é, as primeiras noções do Estado e da sociedade, enquanto elementos primordiais de uma nova concepção do mundo que entra em luta contra as concepções determinadas pelos diversos ambientes sociais tradicionais, ou seja, contra as concepções que poderíamos chamar de folclóricas. O problema didático a resolver é o de abrandar e fecundar a orientação dogmática que não pode existir nestes primeiros anos. $\mathrm{O}$ resto do curso não deveria durar mais de seis anos, de modo que aos quinze ou dezesseis anos, já deveriam estar concluídos todos os graus da escola unitária (GRAMSCI, 2004, p. 37).

$\mathrm{Na}$ assertiva acima, o autor nos fala acerca de questões metodológicas fundamentais, que ocorrem como desdobramento dos princípios e a finalidade que se quer atingir. Acreditamos que essas passagens são as que mais possibilitam um desvirtuamento do pensamento de Gramsci como o teórico da educação. Nesse sentido, apanha-se o que ele 
pontua acerca dessas questões que são específicas do complexo educacional e se arranca todo o resto que nos faz compreender como Gramsci vislumbrava a efetivação desse modelo educacional.

O filósofo italiano nos chama a atenção para o fato de que a resolução do problema da crise que se abate sobre a educação demandaria "uma enorme ampliação da organização prática da escola, isto é, dos prédios, do material científico, do corpo docente, etc." (GRAMSCI, 2004, p. 36). Isto nos possibilita entender que a construção de prédios, a compra de materiais pedagógicos, a ampliação do corpo docente no âmbito da escola pública vão de encontro aos interesses do sistema do capital que visa lucrar com a mercantilização da educação, como ocorre de forma aguda, a propósito, no momento de crise atual em que o capitalismo necessita cada vez mais de mercados e o Estado reduz os gastos, diminuindo as verbas endereçadas à educação, deixando a educação a cargo da iniciativa privada, inclusive corroborando com incentivos fiscais, dentre outras estratégias.

Retomando as questões específicas do complexo educacional, Gramsci (2004, p. 38, grifos nossos) atentava para algumas particularidades importantes, como veremos abaixo:

[...] os alunos urbanos, pelo simples fato de viverem na cidade, já absorveram - antes dos seis anos - muitas noções e aptidões que tornam mais fácil, mais proveitosa e mais rápida a carreira escolar. Na organização interna da escola unitária, devem ser criadas, pelo menos, as mais importantes destas condições, além do fato, que se deve dar por suposto, de que se desenvolverá paralelamente à escola unitária - uma rede de creches $\mathrm{e}$ outras instituições nas quais, mesmo antes da idade escolar, as crianças se habituem a uma certa disciplina coletiva e adquiram noções e aptidões pré-escolares. De fato, a escola unitária deveria ser organizada como escola em tempo integral, com vida coletiva diurna e noturna, liberta das atuais formas de disciplina hipócrita e mecânica, e o estudo deveria ser feito coletivamente, com a assistência dos professores e dos melhores alunos, mesmo nas horas do estudo dito individual, etc.

Algumas dessas questões específicas do complexo educacional elencadas pelo autor, tais como, ensino em creches e a organização de escolas de tempo integral, ainda que em circunstâncias diferentes, já estão 
colocadas em prática na atual rede de ensino, e não só na rede pública, mas, principalmente, na rede de ensino privada, fato esse que reforça a nossa defesa já mencionada de que o problema central da educação não é a falta de conhecimento técnico acerca da melhor solução para os problemas educacionais. Com efeito, a solução desses problemas esbarra nos interesses privados; implica na perda por parte dos grandes capitalistas da educação como uma grande fonte de mercado e de lucros; exige que o Estado rompa com as grandes empresas e deixe de financiar os banqueiros, para investir adequadamente em educação.

Outra questão relativa à proposta educacional de Gramsci é a defesa de uma escola criadora, que se consistiria na fase da disciplina e de elevação de todos os alunos a um mesmo nível de cultura, colocando-os numa fase de conquista da autonomia. Contudo, a escola criadora é uma fase que exige do aluno uma vontade e um interesse espontâneo pelo conhecimento e coloca o professor apenas como um orientador. Nesse sentido, enfatiza Gramsci (2004, p. 39-40) que:

A escola criadora é o coroamento da escola ativa: na primeira fase, tende-se a disciplinar e, portanto, também a nivelar, a obter uma certa espécie de "conformismo" que pode ser chamado de "dinâmico"; na fase criadora, sobre a base já atingida de "coletivização" do tipo social, tende-se a expandir a personalidade, tornada autônoma e responsável, mas com uma consciência moral e social sólida e homogênea. Assim, escola criadora não significa escola "inventores e descobridores"; indica-se uma fase e um método de investigação e de conhecimento, e não um "programa" predeterminado que obrigue à inovação e à originalidade a todo custo. Indica que a aprendizagem ocorre sobretudo graças a um esforço espontâneo e autônomo do discente, e no qual o professor exerce apenas uma função de guia amigável, como ocorre ou deveria ocorrer na universidade.

Observa-se que o construtivismo advoga trabalhar o nível da autonomia e da espontaneidade desde a etapa da educação infantil, o que contraria frontalmente a proposta do intelectual sardo, o qual vislumbra uma autonomia no momento em que o aluno detém uma maturidade intelectual e uma formação moral e cultural sólidas. 
Depois de tecer essas considerações acerca do sistema educacional, antes e depois da reforma Gentile, e de como deveria ser uma Escola Unitária, que unisse desenvolvimento manual e intelectual, o autor começa a tecer maiores observações acerca do princípio educativo. De acordo com Gramsci (2004, p. 42-43, grifo nosso),

[...] Com seu ensino, a escola luta contra o folclore, contra todas as sedimentações tradicionais de concepções de mundo, a fim de difundir uma concepção mais moderna, cujos elementos primitivos e fundamentais são dados pela aprendizagem da existência de leis naturais como algo objetivo e rebelde, às quais é preciso adaptarse para dominá-las, e de leis civis e estatais, produto de uma atividade humana, que são estabelecidas pelo homem e podem ser por ele modificadas tendo em vista seu desenvolvimento coletivo; a lei civil e estatal organiza os homens do modo historicamente mais adequado a dominar as leis da natureza, visando a transformá-la e socializá-la cada vez mais profunda e extensamente [...].

Parece-nos que aqui há um discurso que começa como constatação da escola existente e avança na direção do discurso e da defesa de um novo Estado, hipoteticamente aqui analisado como Estado operário. Gramsci tece essas considerações constatando que, nesse momento histórico de surgimento de uma sociedade moderna, com o advento da industrialização, a escola cumpre a função de lutar contra as velhas visões de mundo das civilizações tradicionais, no intuito de criar nos indivíduos uma nova maneira de conceber a vida, e isso ocorre mediante o ensino das ciências da natureza (leis naturais), que permite ao homem "adaptar-se para dominálas", e das leis que regem a sociedade (leis civis e estatais), tais leis são criadas pelo conjunto dos homens e por isso elas podem ser transformadas, recriadas, assinalando que essas leis são criadas mediante o objetivo de organizar os homens na produção de sua subsistência, ou seja, no trabalho. É interessante observar nessa passagem a definição de trabalho, que se coaduna com aquela explicitada na ontologia marxiana, revigorada por Luckács, a partir da qual o trabalho é concebido como a mediação do homem com a natureza. Complementando a linha de raciocínio, Gramsci (2004, p. 43, grifos nossos) continua afirmando que, 
[...] pode-se dizer, por isso, que o princípio educativo no qual se baseavam as escolas primárias era o conceito de trabalho, que não pode se realizar em todo seu poder de expansão e de produtividade sem um conhecimento exato e realista das leis naturais e sem uma ordem legal que regule organicamente a vida dos homens entre si, ordem que deve ser respeitada por convicção espontânea e não apenas por imposição externa, por necessidade reconhecida e propostas a si mesmos como liberdade e não por simples coerção. O conceito e o fato do trabalho (da atividade teórico-prática) é o princípio educativo imanente à escola primária, já que a ordem social e estatal (direitos e deveres) é introduzida e identificada na ordem natural pelo trabalho.

O autor, ao avançar sobre o discurso acerca da escola existente, constata que as escolas primárias se organizavam mediante o trabalho, ou seja, era uma escola que se destinava a ensinar aos seus alunos noções concretas sobre as leis naturais e sociais, afirmando, pois, o trabalho como o "princípio educativo imanente à escola primária”. Gostaríamos de destacar que, no nosso entender, o autor tem nas relações sociais de produção, no trabalho, o elemento determinante de qualquer forma de sociabilidade, portanto, como categoria fundante do mundo dos homens ${ }^{3}$ - conforme o legado marxiano-lukácsiano, ao qual Gramsci se refere como imanente para nortear a organização e o programa escolar, “já que a ordem social e estatal (direitos e deveres) é introduzida e identificada na ordem natural pelo trabalho". Nessa direção, explica Gramsci (2004, p. 43, grifos nossos), que:

O conceito do equilíbrio entre ordem social e ordem natural com base no trabalho, na atividade teóricoprática do homem, cria os primeiros elementos de uma intuição do mundo liberto de toda magia ou bruxaria, e fornece $o$ ponto de partida para o posterior desenvolvimento de uma concepção histórica, dialética, do mundo, para a compreensão do movimento e do devir, para a avaliação da soma de esforços e de sacrifícios que o presente custou ao passado e que o futuro custa ao presente, para a concepção da atualidade como síntese do passado, de todas as gerações passadas, que se projeta no futuro. É este o fundamento da escola primária; que ele tenha dado todos os seus frutos, que no corpo de professores tenha existido a consciência de seu dever e

3 Sobre o caráter ontológico do trabalho, como categoria fundante do mundo dos homens, conforme recuperada por Lukács do legado marxiano, conferir Lessa, 1997. 
do conteúdo filosófico deste dever, é um outro problema, ligado à crítica do grau de consciência civil de toda a nação, da qual o corpo docente era apenas uma expressão, ainda que amesquinhada, e não certamente uma vanguarda.

Aqui encontramos uma ratificação do conceito de trabalho "atividade teórico-prática do homem", que deve servir de base para um equilíbrio entre ordem social e natural (conhecimento das leis naturais e sociais). Esse equilíbrio é o ponto de partida para "o posterior desenvolvimento de uma concepção histórica", uma nova concepção de mundo, para compreender e avaliar a "soma de esforços e sacrifícios que o presente custou ao passado e que o futuro custa ao presente", ou seja, utilizarmos o passado para compreender o presente e planejar o futuro.

Gramsci vai encerrando suas elaborações chamando a atenção para a função social da escola na sociedade de classes. Vale à pena conferir a citação que trata dessa questão:

A escola tradicional era oligárquica já que se destinava à nova geração dos grupos dirigentes, destinada por sua vez a tornar-se dirigente: mas não era oligárquica pelo seu modo de ensino. Não é a aquisição de capacidades de direção, não é a tendência a formar homens superiores que dá a marca social de um tipo de escola. A marca social é dada pelo fato de que cada grupo social tem um tipo de escola próprio, destinado a perpetuar nestes estratos numa determinada função tradicional, dirigente ou instrumental. Se se quer destruir esta trama, portanto, deve-se não multiplicar e hierarquizar os tipos de escola profissional, mas criar um tipo único de escola preparatória (primária-média) que conduza o jovem até os umbrais da escolha profissional, formando-o, durante este meio tempo, como pessoa capaz de pensar, de estudar, de dirigir ou de controlar quem dirige (GRAMSCI, 2004, p. 49).

Feitas essas considerações iniciais acerca do Caderno 12, consubstanciadas em forma de ensaios de compreensão, finalizamos indicando duas questões que perseguiremos no curso de nossos estudos.

Entendemos que Gramsci, no Caderno 12, parte da constatação de que o sistema educacional italiano se encontra em crise, e que essa crise de "princípios" se materializaria em uma cisão entre ensino técnico e ensino 
intelectual, que ocorreu com o advento da sociedade industrial moderna.

O debate em torno da escola unitária e a investigação acerca do trabalho como princípio educativo parece implicar, então, duas discussões que se complementam e, por isso, se encontram totalmente imbricadas, portanto, ao nosso ver, precisam ser estudadas de maneira a compreender a relação existentes entre ambas.

Primeiro, a fórmula da Escola Unitária e a constante defesa do princípio humanista, deixa-nos claro que Gramsci não estava defendendo formar para o mercado de trabalho, nem tão pouco desconsiderando o fato de termos sob a forma do capitalismo uma cisão entre trabalho manual e intelectual.

Segundo, entendemos que Gramsci pensa a Escola Unitária não para esse momento histórico contra-revolucionário, nem para o comunismo, uma sociedade já emancipada, e sim para um momento transitório, em que a classe revolucionária toma o poder, pois nessa transição o Estado operário organizará a sociedade e, conseqüentemente, o novo sistema educacional. Tratar-se-á de um período de transição, onde as transformações são processuais, no entanto, inaugurado e só possível com uma ruptura radical com o sistema do capital, ou seja, com a revolução proletária.

\section{Referências bibliográficas}

COSTA, Frederico. Ideologia e educação na perspectiva da ontologia marxiana. 2007. 157 f. Tese (Doutorado em educação) - Universidade Federal do Ceará, Fortaleza, 2007.

GRAMSCI, Antônio. Cadernos do cárcere, vol. 2, 2 ed. Rio de Janeiro: Civilização Brasileira, 2001.

JIMENEZ, Susana; MENDES SEGUNDO, Maria das Dores. Erradicar a pobreza e reproduzir o capital: notas críticas sobre as diretrizes para a educação no novo milênio. Cadernos de Educaşão, Pelotas, ano 16, n. 28, p. 119-138, janjun 2007.

LESSA, Sérgio. A ontologia de Lukács. $2^{a}$ Ed. Maceió - Ed.UFAL, 1997.

MANACORDA, Mario Alighiero. O principio educativo em Gramsci. 1 ed. 
Tradução de Willian Lagos. Porto Alegre: Artes médicas, 1990.

NOSELLA, Paolo. A escola de Gramsci. 1 ed. Porto Alegre: Artes Médicas, 1992.

TONET, Ivo. Educação, cidadania e emancipação humana. 1 ed., Rio Grande do Sul; Ed. Unijuí, 2005. (Coleção fronteiras da educação). 